\title{
Melanophores: Smooth Muscle Cells in Disguise
}

\author{
Saima Salim and Sharique A. Ali
}

Additional information is available at the end of the chapter

http://dx.doi.org/10.5772/48256

\section{Introduction}

Melanophores are specialized cells derived from the neural crest that contain membrane bound vesicles called melanosomes. Melanosomes are filled with melanin, a dark, nonfluorescent pigment that plays a principal role in physiological color adaptation of animals. Melanophores regulate melanosome trafficking on cytoskeletal filaments to generate a range of striking chromatic patterns. The mechanism of physiological color change by these melanophores encompasses both physical and biochemical aspects of melanosome dynamics. Melanophores aggregate or disperse their melanosomes when the host requires changing its color in response to the environmental cues (e.g., social interactions or camouflage). Interestingly, morphological, embryological and physiological evidence has revealed that melanophores of fish, amphibian and reptiles are functionally modified smooth muscle cells [1]. Moreover, during contraction of melanophore there is an aggregation of melanin granules which is to be considered the visible counterpart of an aggregation of colloidal particles that occur during smooth muscle contraction. The biochemical events underlying melanosome dispersion is analogous to those for smooth muscle relaxation: both processes result from increase in cAMP levels and require the presence of extracellular Ca2+ for their action.

\subsection{Regulation of smooth muscle contraction}

Ligands like neurotransmitters and hormones bind to specific receptors to activate contraction in smooth muscle. Subsequent to this binding there is an increase in cellular phospholipase $C$ activity via coupling to a $G$ protein resulting into the activation of a membrane phospholipid phosphatidylinositol 4, 5-biphosphate $\left(\mathrm{PIP}_{2}\right)$. Phospholipase $\mathrm{C}$ (PLC) produces two potent second messengers from PIP2: Diacylglycerol (DAG) and inositol 1, 4, 5-triphosphate (IP3). IP3 binds to specific receptors, causing release of calcium $\left(\mathrm{Ca}^{2+}\right)$. Later in the cascade DAG activates PKC, which further phosphorylates specific target proteins. In smooth muscles PKC promotes phosphorylation of $\mathrm{Ca}^{2+}$ 
channels that regulates cross-bridge cycling. $\mathrm{Ca}^{2+}$ binds to a calcium modulated protein called calmodulin, resulting into the activation of MLC kinase, which is a myosin light chain protein [2]. This step initiates the shortening of the muscle cell together with actin via cross bridge cycling. The state of contraction is maintained by a $\mathrm{Ca}^{2+}$ sensitizing mechanism that is brought about by another protein, Rho kinase also known as ROCK. ROCK increases the activity of the motor protein myosin II by two different mechanisms: Firstly, phosphorylation of the myosin light chain (MLC) increases the myosin II ATPase activity. Thus several bundled and active myosins, which are asynchronously active on several actin filaments, move actin filaments against each other resulting in the net shortening of actin fibres. Secondly by inactivating MLC phosphatase, leading to increased levels of phosphorylated MLC [2, 3, 100]. (Figure 1)

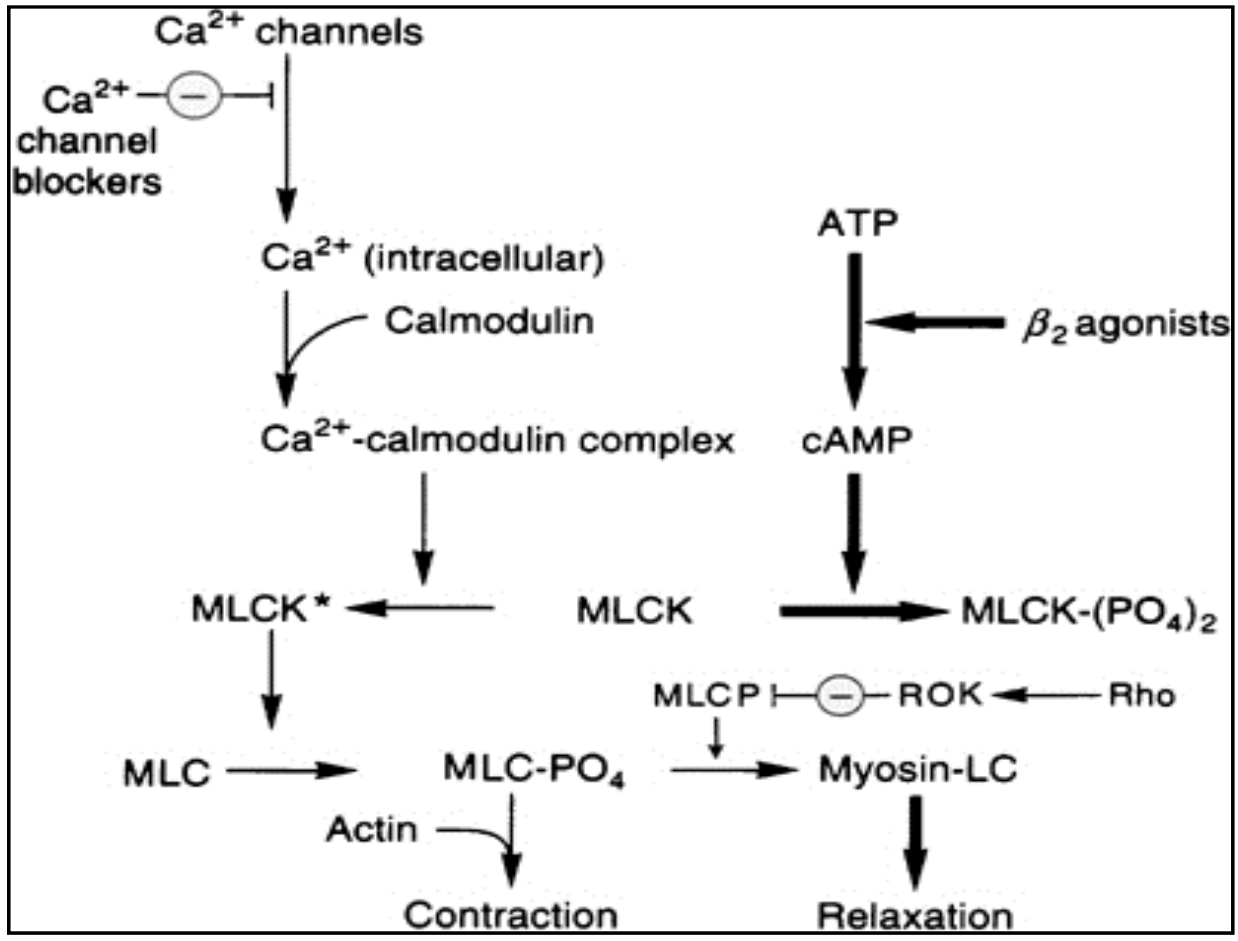

Figure 1. Regulation of Smooth Muscle Contraction and Relaxation. Contraction is triggered by the influx of calcium through the transmembrane channels (ligand-gated (noradrenaline) and the voltagegated $\mathrm{Ca}^{2+}$-channels). The calcium combines with calmodulin to form a complex that converts myosin light chain kinase to its active form $\left(\mathrm{MLCK}^{*}\right)$. The latter phosphorylates the myosin light chains (MLC), thereby initiating the interaction of myosin with actin. Activation of RhoA leads to the activation of Rho-kinase (ROCK), which in turn phosphorylates the regulatory myosin-binding subunit of myosin phosphatase (MLCP), resulting into the inhibition of the enzyme. Substances that increase the cAMP may cause relaxation in smooth muscle by accelerating the inactivation of MLCK and facilitating the expulsion of calcium from the cell. (Reproduced with permission from Macmillan Publishers Ltd: [100] Internat. Journ. of Impot. Res. 16: 459-469, Copyright (c) 2004, Nature Publishing Group. 


\subsection{Regulation of smooth muscle relaxation}

The process of relaxation requires a decreased intracellular $\mathrm{Ca}^{2+}$ concentration and increased myosin light chain (MLC) phosphatase activity. The plasma membrane contain $\mathrm{Ca} \mathrm{Mg-}$ ATPases along with $\mathrm{Na}^{+} / \mathrm{Ca}^{2+}$ exchangers that remove $\mathrm{Ca}^{2+}$ from the cytosol. Also the voltage operated $\mathrm{Ca}^{2+}$ channels in the plasma membrane close to the entry of $\mathrm{Ca}^{2+}$ in the cell resulting into relaxation [2].

In short the contractile activity in smooth muscle is initiated by a $\mathrm{Ca}^{2+}$-calmodulin interaction to stimulate phosphorylation of the light chain of myosin. A Ca2+ sensitization of the contractile proteins is signaled by the RhoA/Rho kinase pathway to inhibit the dephosphorylation of the light chain by myosin phosphatase, maintaining force generation. Removal of $\mathrm{Ca} 2+$ from the cytosol and stimulation of myosin phosphatase initiate the process of smooth muscle relaxation $[2,100]$ (Figure 1).

\section{Historical and comparative perspective of melanophores with reference to smooth muscles}

The comparison of melanophores to smooth muscle cells dates back as early as 1917 when Spaeth provided evidence for the similarity of melanophores with smooth muscle cells. Rhythmical pulsations in the isolated scale melanophores of Fundulus heteroclitus were first observed by Spaeth [1]. The observation followed by the in depth analysis of the behavior and responses of melanophores to various stimuli and their parallelism to smooth muscle cells led to the conceptualization of melanophore as a modified derivative of smooth muscle. Rhythmical movements are, of course, intimately associated with this latter tissue and their persistence for considerable periods of time in isolated strips of the esophagus and stomach of frogs and other vertebrates is well known. The rhythmical movements in isolated scale melanophores are comparable and perhaps similar to these movements in smooth muscle. This discovery opens a new field for research that might contribute in understanding the ramifications of inter and intra-cellular dynamics.

The biochemical events underlying the melanosome dispersion are analogous to smooth muscle relaxation since both these processes result from an increase in cyclic AMP (cAMP) levels [102]. Unlike cardiac muscle, increased cAMP in smooth muscle causes relaxation. The reason for this is that cAMP normally inhibits myosin light chain kinase (MLCK), the enzyme that is responsible for phosphorylating smooth muscle myosin and causing contraction. It is known that the increase in cAMP initiates the influx of $\mathrm{Ca}^{2+}$ from the cytoplasm to the endoplasmic reticulum and/or mitochondria or out of the smooth muscle cell. Whereas the melanosome dispersion progresses in the absence of $\mathrm{Ca}^{2+}$ and presence of extracellular $\mathrm{Ca}^{2+}$ (from the action of MSH) [4]. The crucial role of $\mathrm{Ca}^{2+}$ and $\mathrm{MSH}$ in the bidirectional movement of melanophores has been shown in the figure 2. Extracellular stimuli (either hormonal; adrenaline or mechanical stimulus) could result in inward movement of $\mathrm{Ca}^{2+}$ from the extracellular matrix. This is followed by activation of phospholipase C (PLC) promoting 1) inositol trisphosphate (IP3)-dependent release of $\mathrm{Ca}^{2+}$ 
from intracellular stores and 2) diacylglycerol (DAG)-sensitive activation of protein kinase C (PKC), which facilitates $\mathrm{Ca}^{2+}$ entry through voltage-dependent calcium channels, resulting into pigment aggregation. Stimulation of alpha MSH receptor that couples to Gs $\alpha$ proteins stimulates adenylyl cyclase and increase intracellular cAMP resulting into pigment dispersion by activating a calcium pump that drives the expulsion of calcium out from the cells resulting into pigment dispersion. In the case of pigment cells the action of Melanocyte concentrating hormone $(\mathrm{MCH})$ is enhanced by the absence of intracellular $\mathrm{Ca}^{2+}[5,101]$ which in the case of smooth muscle may be an apparent counterpart triggered by $\beta$ adrenergic receptors (NE or noradrenaline). The actual process of how melanosomes translocate from the concentrated to dispersed state and vice versa is not completely unfurled. However the mechanism is highly coordinated and requires a multitude of factors and entities.

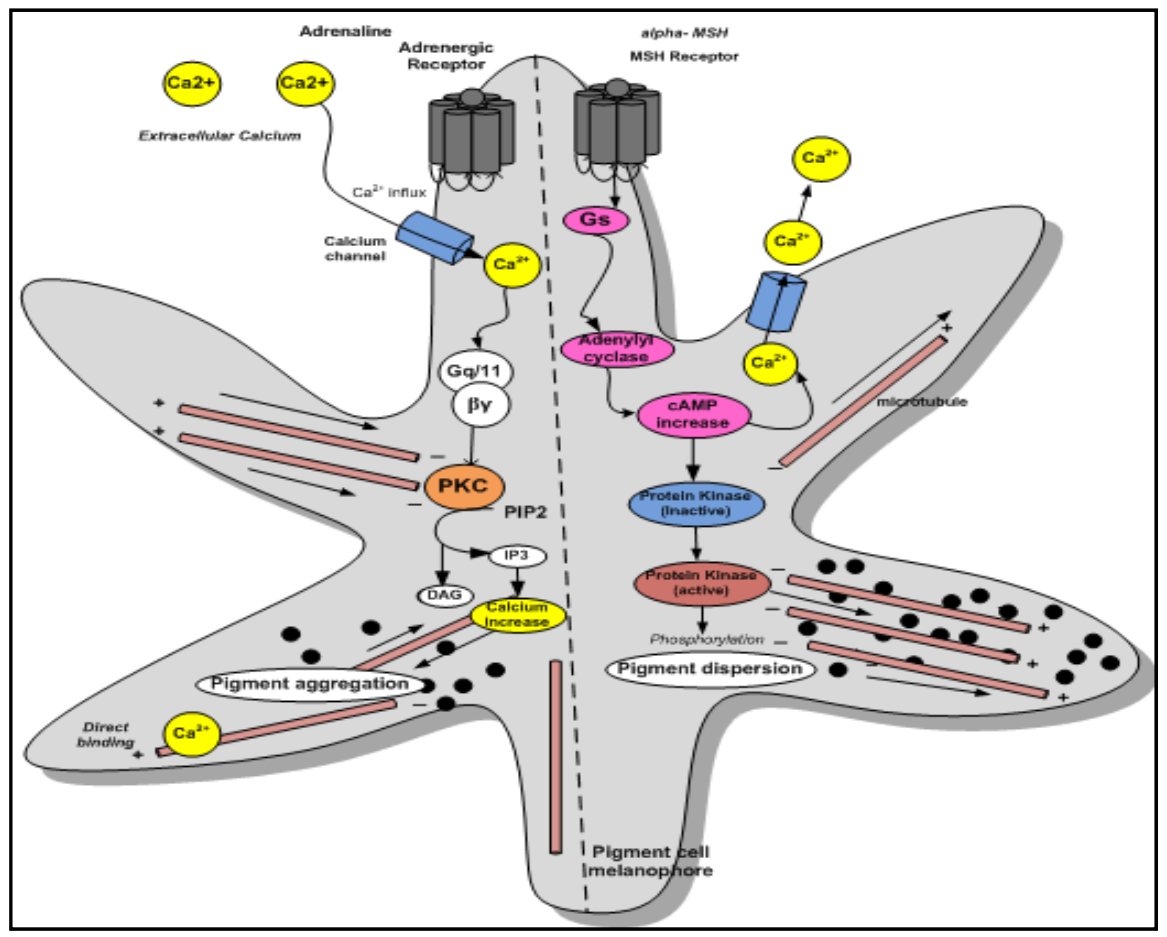

Figure 2. Model for the crucial role of $\mathrm{Ca}^{2+}$ and $\mathrm{MSH}$ in the bidirectional movement of melanophores. Extracellular stimuli (either hormonal; adrenaline or mechanical stimulus) could result in inward movement of $\mathrm{Ca}^{2+}$ from the extracellular matrix. This is followed by activation of phospholipase C (PLC) promoting 1) inositol trisphosphate (IP3)-dependent release of $\mathrm{Ca}^{2+}$ from intracellular stores and 2) diacylglycerol (DAG)-sensitive activation of protein kinase $\mathrm{C}(\mathrm{PKC})$, which facilitates $\mathrm{Ca}^{2+}$ entry through voltage-dependent calcium channels, resulting into pigment aggregation. Stimulation of alpha MSH receptor that couples to Gs $\alpha$ proteins stimulates adenylyl cyclase and increase intracellular cAMP resulting into pigment dispersion by activating a calcium pump that drives the expulsion of calcium out from the cells resulting into pigment dispersion 


\section{Experiments}

Since all muscle cells are "excitable cells," i.e., they are capable of responding to appropriate stimulation. The response to this is contraction, however the stimulus can vary. It may be an electrical signal or depolarization produced at the surface of the muscle cell by the activity of neurons. Some muscle cells (particularly smooth muscle) respond not only to neuronal signaling, but to direct chemical or mechanical stimulation [6]. Hormonal signals can cause contraction in some situations. Interestingly, melanophores have an instinctive ability to quickly reposition pigment granules within the cells on given appropriate stimulus. The responses of melanophores to external stimuli are highly coordinated; where external signals are received and integrated, thereby eliciting a concerted and appropriate response $[7,8]$. This cellular communication depends largely on the transmission of signal couriers (i.e. "ligands/agonist") which are received via cell surface and intracellular recognition molecules (i.e. "receptors") on the recipient cells, resulting into remarkably coordinated bidirectional movement of pigment granules within the cells $[7,8]$.

By far the most striking resemblance between the melanophores and smooth muscle cells has been furnished on physiological grounds [9, 1]. Also the morphological, as well as embryological evidence has been brought to light that supports the idea that color changes in the three groups of lower vertebrates; fishes, amphibians and reptiles along with crustaceans and cephalopods are brought about by responses of specialized functional smooth muscle cells [10, 11, 12].

The most striking evidence of resemblance between smooth muscles and melanophores in terms of physiological basis was provided as early as 1906 by Franz [13]. He recorded the similarity between the physiological responses of the sphincter papillae in Acanthias and the dermal melanophores of frog. A number of investigators have demonstrated the involvement of nervous system and direct innervations of chromatophores. This view has been widely accepted by a number of workers and a significant amount of reports have been published [14, 15, 16, 17].

\subsection{Innervation}

There is a certain resemblance between the mechanisms coordinating the mechanism of smooth muscles with that of vertebral melanophores in terms of innervation. Both are controlled by sympathetic nervous system and influenced by hormonal secretion during nervous excitement $[16,18,8]$. In the case of smooth muscles, however there is an autonomic innervation of antagonistic fibers that are morphologically distinct. Interestingly, the neural control of skeletal muscles differs significantly from that of smooth muscles. A skeletal muscle fiber has only one junction with a somatic nerve fiber, and the receptors for the neurotransmitter are located only at the neuromuscular junction [19]. By contrast, the entire surface of smooth muscle cells contains neurotransmitter receptor proteins. Neurotransmitter molecules (norepinephrine) are released along a stretch of an autonomic nerve fiber that is located some distance from the smooth muscle cells and stimulate a number of smooth muscle cells [20]. 
The innervation of the melanophores has been demonstrated physiologically in several species of teleosts [22, 23, 24, 1]. As early as 1876, Pouchet [21] reported that in teleost fishes, the sectioning of peripheral nerves or the electrical stimulation of spinal nerves led respectively to the darkening or paling in definite areas, claiming the innervation to be of sympathetic nature. Interestingly, the surface of melanophores contains numerous receptors of neurotransmitters as well as hormones including adrenoceptors [8]. It is now generally accepted that the melanophores are sympathetically innervation and the catecholamines released from the adrenergic fibers are responsible for causing pigment aggregation.

\subsection{Effect of light}

Interestingly it has been demonstrated that the excised iris of certain fishes (elasmobranchs and teleosts) and amphibians responds to illumination by contraction of sphincter papillae. Also a light induced stimulation in chromatophores of cephalopods, Octopus and Loligo have been demonstrated [25], which was a direct result of contraction and relaxation of radially arranged smooth muscles. In another report the smooth muscle cells of the frog, (Rana pipiens) iris sphincter also showed light-evoked contraction [26]. In general, melanosome movements in fish melanophores are controlled by adrenergic nerves. That means that the melanosomes aggregate in the presence of epinephrine and the aggregation is inhibited by $\alpha$-adrenergic blocking drugs [104,105]. The light-sensitive cultured melanophores also aggregate on application of epinephrine (Wakamatsu, 1978). Dibenamine ( $\alpha$-adrenergic blocker) inhibited the response to epinephrine, but did not inhibit the lightinduced melanosome aggregation (Wakamatsu, unpublished observation). These facts suggest that light controls the melanosome movements without mediation of the adrenergic receptors and acts directly on phosphodiesterase enzyme systems in the light-sensitive melanophores.

\subsection{Mechanical stimulation}

It has been reported that gentle stretching or pinching of excised pieces of fish and frog stomach and esophagus induced powerful contractions, provided the stimulus has not been too violent. Similarly, melanophores from the portions of skin of Loligo resulted into wide expansion. Single aggregated melanophores from isolated scales of the angelfish, Pterophyllum scalare were submitted to mechanical compression with forces ranging from 50-320 $\mu \mathrm{p}$. With increasing force melanophores disperse their pigment, the degree of dispersion being proportional to the intensity of the force [27].

\subsection{Electrical stimulation}

The responses of several types of smooth muscles as well as the melanophores from the three groups of lower vertebrates show considerable similarity in their contraction to faradic stimulation. 
It has been reported that sphincter papillae of eel and frog (Rana) contracted when stimulated electrically. Likewise the radial muscles of the chromatophores of cephalopods also respond to electrical stimulation by contracting [15]. Such contractions have been seen in strips of frog stomach and the digestive tube of several species of teleosts. Such parallelism in responses to melanophores on stimulation with induction currents of sufficient intensity and durations have been observed as well. Fundulus melanophores contract invariably when proper strength and duration of current and salt concentration of mounting medium was selected [1]. Similar results were observed with melanophores of Rana esculenta and Hyla arborea [28]. The reports by Bert and Krukenberg [29, 30] were in line with the original observation of Brücke that the direct faradic stimulation of excised chameleon skin pieces produced paling or lightening by contraction of melanophores. Since the nervous system of lower vertebrates like fish has evolved to allow faster chromatic adaptation, the sympathetic division of the autonomic nervous system has been shown to be involved in aggregation of pigment in melanophores.

\subsection{Chemical and pharmacological stimulation}

Effect of various chemicals and pharmacological compounds has been extensively studied on pigment as well as muscle cells. The responses to various biogenic amines/ compounds and neurotransmitters have been analyzed and it is confirmed that the effector cells contain several types of receptors for different neurotransmitters and hormones [8]. The extracellular signals are translated by the receptor system into an increase or a decrease in levels of intracellular second messenger. Until recently three kinds of second messengers were known to take part in the motile responses of chromatophores, namely cyclic adenosine mono phosphate (cAMP), Calcium $\left(\mathrm{Ca}^{2+}\right)$, and inositol 1,4,5 tri-phosphate (IP3). Interestingly the roles of these second messengers in smooth muscle contraction have been described [31, 32].

Calcium is one of the most important cations in terms of diversity of function and has a crucial role in muscle contraction and pigment translocation respectively (due to the extent of depth only the role of $\mathrm{Ca}^{2+}$ is discussed). The role of $\mathrm{Ca}^{2+}$ in the process of muscle contraction and relaxation has been reviewed by Karaki et al., in quite detail [103].

In smooth muscle, the influx of calcium leads to depolarization. There calcium binds to calmodulin, causing the calmodulin-caldesmon complex to change its configuration and pull the caldesmon away from the myosin binding sites on the actin strand. The myosin heads bind to actin resulting into muscle contraction. Calcium ions are required in the medium for the full darkening action of melanocyte- stimulating hormone. It has been reported that frog (Rana pipiens) skin the action of melanocyte-stimulating hormone involves the production of pigment granule movements as a result of the interaction of calcium ions with intracellular microfilaments and possibly by the breakdown of microtubules [ 33, 34] In relation to the nervous system controlling fish chromatophores [35] first reported that $\mathrm{Ca}^{2+}$ is required for catecholamine release from the sympathetic nerve terminals in the goby Chasmichthys gulosus. It has been suggested that $\mathrm{Ca}^{2+}$ act as the coupling agent in muscle excitation and contraction. Fish chromatophores provide an ideal cell model for studying the regulation of directional, 
microtubule-based organelle trafficking [36, 37, 38]. Pigment granules in these cells exhibit distinct movements, which are closely associated with and dependent upon a dense radial array of microtubules [39, 40,41]. This transport is either completely retrograde (inward aggregation toward the "minus'-ends of microtubules at the cell center) or completely anterograde (outward dispersion toward the "plus'-ends at the cell periphery). Thus, the cellular events that signal a specific directional organelle movement can be manipulated and studied. The data supporting the role of $\mathrm{Ca}^{2+}$ in the regulation of pigment movement is quite convincing. Studies using ionophores $[42,43]$ or lysed cell models [44] have implicated a $\mathrm{Ca}^{2+}$ based regulatory system in erythrophores. Raising $\mathrm{Ca}^{2+}$ in these two models causes aggregation, and lowering $\mathrm{Ca}^{2+}$ causes dispersion, suggesting that intracellular $\mathrm{Ca}^{2+}$ is the exclusive regulatory signal for both aggregation and dispersion.

Another signaling molecule Nitric oxide (NO) plays a significant role in a number of cellular processes like the relaxation of blood vessels, sperm motility, and polymerization of actin. It has been found that the signal transduction by NO can be mediated through the activation of soluble guanylate cyclase (sGC), which leads to increased production of cGMP and activation of cGMP-dependent kinases (PKG) [108]. Studies show that melanosome aggregation depends on synthesis of NO, and NO deprivation causes dispersion indicating a crucial role of NO and cGMP in regulation of melanosome translocation. Similar results have been reported by other workers on teleostean melanophores [109]. Interestingly the parallelism of NO action in terms of smooth muscles can be drawn since increased intracellular cGMP by NO, inhibits calcium entry into the cell, thereby decreasing intracellular calcium concentrations and causing smooth muscle relaxation. $\mathrm{NO}$ also activates $\mathrm{K}^{+}$channels, which leads to hyperpolarization and relaxation. Finally, NO acting through cGMP can stimulate a cGMP-dependent protein kinase that activates myosin light chain phosphatase that dephosphorylates myosin light chains, which leads to relaxation (Figure 3).

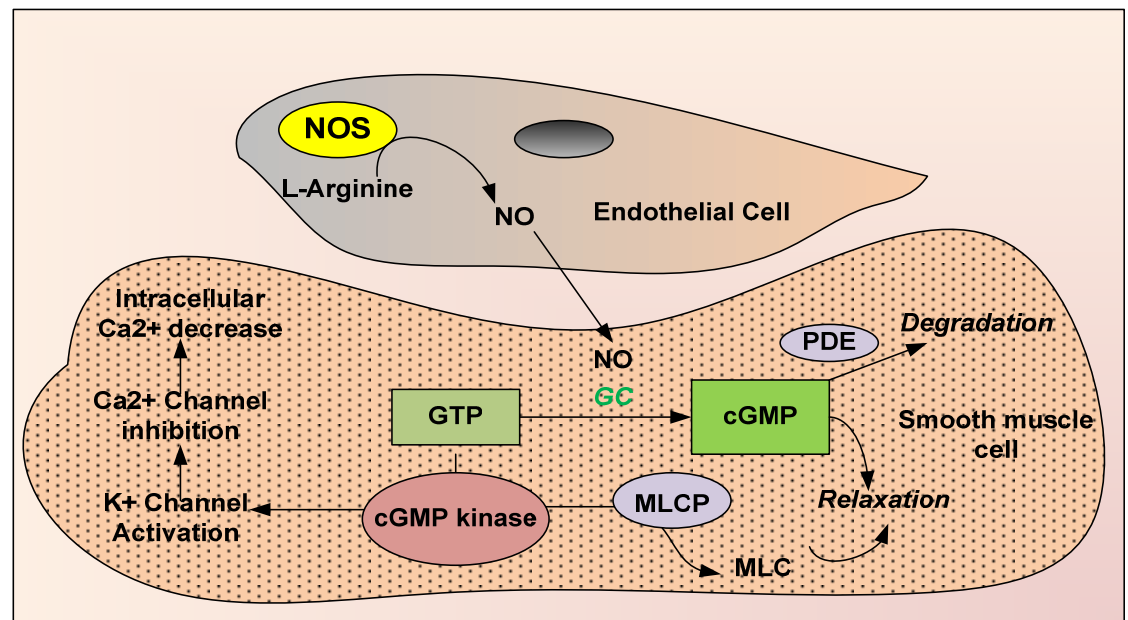

Figure 3. NO induced smooth muscle Relaxation, NO; nitric oxide, NOS; nitric oxide synthase, GC; guanylyl cyclase, PDE cyclic GMP-dependent phosphodiestrase, MLC lyosin light chain 


\section{Immunocytochemical experiments to reveal the involvement of similar intercellular proteins in melanophores and smooth muscle}

Immunocytochemical experiments conducted on the melanophores, xanthophores, and iridophores from the skins of the two Antarctic fish species Pagothenia borchgrevinki and Trematomus bernacchii tested for a variety of muscle proteins confirmed the presence of actin, myosin, and calmodulin, for all three chromatophores types of the two fishes [46]. Interestingly, the presence of caldesmon and calponin that are both characteristic proteins of smooth muscle fibers have also been found. It has been suggested that calponin's role, in the presence of $\mathrm{Ca}^{2+}$ and calmodulin, is that of a modulator and that caldesmon, a molecule that competes with calponin for actin binding sites, is in a position in which it can switch on and off $\mathrm{Ca}^{2+}$-dependent contractility and relaxation. It is not known at this stage whether these proteins occur also in the chromatophores of other fishes and are not restricted to Antarctic species. Since the control of pigment translocation in fish chromatophores and the regulation of smooth muscle tension both involve the sympathetic nervous system, the presence of similar target proteins in both the systems is quite convincing. Also the fact that none of the chromatophores tested positive for troponin (a characteristic regulatory protein in skeletal and cardiac muscle but not in smooth muscle) shows that there is no close relationship between pigment cells and striated muscle. Also the presence of alpha-actinin (a typical actin binding protein) in melanophores and xanthophores unlike iridophores could be most likely due to greater degree of pigment translocation within the former class of cells $[45,46]$.

\section{Implication of motor proteins and their dynamics in pigment translocation within melanophores}

The cytoskeleton is now no longer considered to be a rigid scaffold, but instead is viewed as a complex and dynamic network of protein filaments that can be modulated by internal and external cues. Three cytoskeletal polymers- actin filaments, microtubules and intermediate filaments cooperate to maintain the physical integrity of eukaryotic cells and, together with molecular motors, allow cells to move themselves and their intracellular organelles like melanosomes. Pigment cells provide an excellent model to study organelle transport as they specialize in the translocation of pigment granules in response to defined chemical cues. Pigment cells of lower vertebrates have traditionally been used as a model for these studies as they transport pigment organelles in a highly concerted and coordinated fashion. These cells can be cultured and transfected, are ideal for biochemical and in vitro studies. Changes in pigment translocation can be easily monitored under light microscopy. Many important mechanism of organelle transport like the regulation and interactions of cytoskeletal filaments (actin and microtubules) and motor proteins have been studied using pigment cells of lower vertebrates. Genetic studies of mouse melanocytes allowed the discovery of essential elements involved in organelle transport including the myosin-Va motor and its receptor and adaptor molecules on the organelle surface [47]. Future studies of pigment cells will contribute in unraveling the mechanisms of regulation of microtubule motors and other related mechanisms that may involve the cooperation of motor proteins. 


\subsection{Molecular mechanism of intracellular translocation of pigment granules}

The most interesting example of organelle transport is within melanophores of lower vertebrates where the cytoskeletal actin and microtubules act in cooperation. The melanophores contain a radial array of $~ 1000-2000$ microtubules [48, 40, 49]. The bidirectional movement of pigments occurs along the radially-organized microtubule cytoskeleton of these cells and also transported along filamentous actin [50]. Microtubules act as tracks for the transport of several intracellular organelles, including pigment vesicles, melanosomes. The trafficking of melanosomes is controlled by two classes of microtubuleassociated motor proteins, kinesins, and cytoplasmic dyneins. Kinesins power the plus-enddirected microtubule-based motility, while cytoplasmic dyneins drive the minus end motility [51, 52]. Dyneins and kinesins also have well-established roles in retrograde (aggregation) and in anterograde (dispersion) transport of melanosomes [53, 54, 55, 56]. In microtubule-poor regions of the cell, pigment granules are transported along microfilaments powered by a myosin motor.

\subsection{Xenopus laevis melanophore system: A fascinating example of organelle transport}

Xenopus laevis melanophore system represents one of the most interesting mechanisms of organelle transport. The pigment transport is regulated by the intracellular levels of cAMP (Figure 4). Up-regulation (induces dispersion) and down regulation (induces aggregation) of cAMP levels are triggered by Melanocyte stimultating hormone (MSH) and Melatonin respectively [57]. This antagonistic action of hormones that regulates pigment translocation within the cells is carried by kinase and phosphatase activities [58].

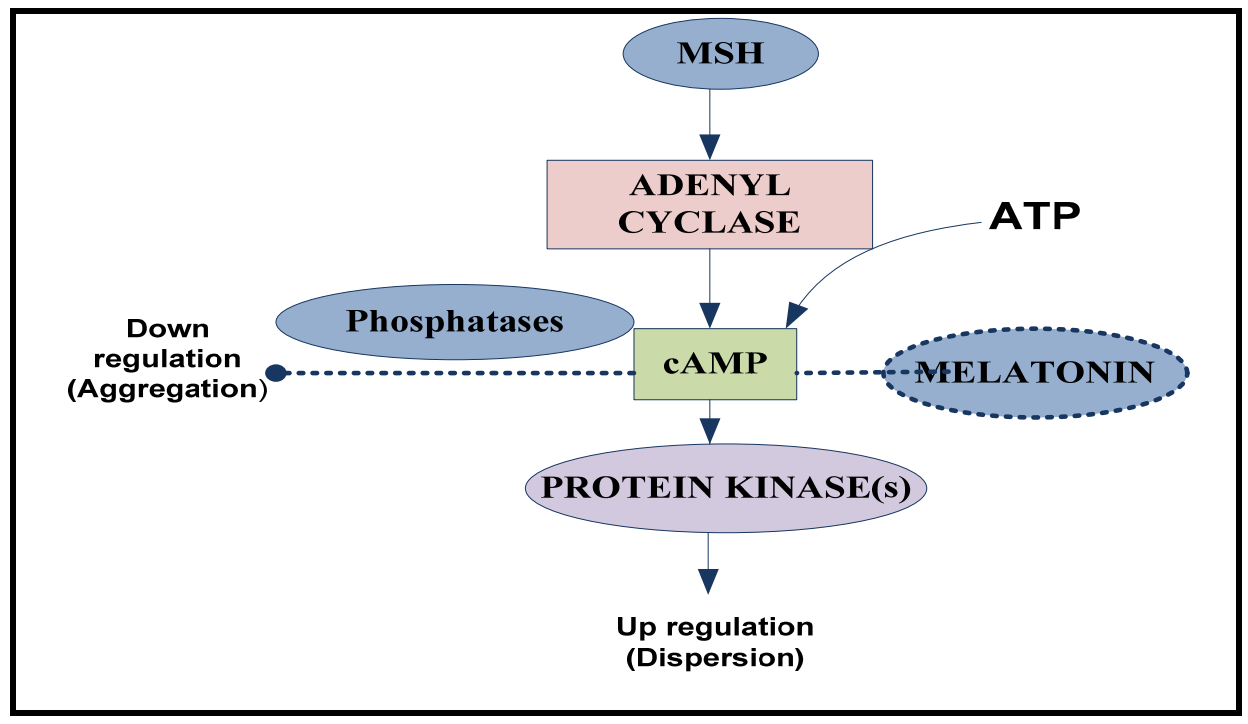

Figure 4. Involvement of cAMP in melanosome movement 


\subsubsection{Cytoskeletal tracks: Microtubule and actin filaments}

Although actin filaments and microtubules differ in origin and structure, their shared features reflects extensive convergence of function. The microtubules and actin filaments show tremendous interaction by binding of several motors to the same cargo at the same time, and movement of pigment granules along both types of cytoskeleton tracks. Studies have demonstrated that the microtubule motor activity is coordinated while the microtubule and actin-based transport are competitive [59]. The direction of melanosome movement is determined by the orientation of plus and minus ends of microtubules and actin filaments within the melanophores [60]. As in most cells, melanophore microtubules are oriented with the minus ends located at the nucleus and their plus ends toward the periphery near the plasma membrane [61, 47]. In melanophores, melanosome aggregation and dispersion are achieved by minus- and plus-end directed movement respectively [59]. In contrast to microtubule organization which is typically in the center of the cells, actin filaments are randomly oriented in a form of a meshwork close to the plasma membrane. The filaments consist of globular subunits arranged head-to-tail into double helical polymers, giving the structure polarity [62]. Actin filaments are required for complete melanosome dispersion but also for maintenance of the dispersed state [34].

\subsubsection{Kinesin and dynein}

Kinesin and Dynein are key entities of microtubule-based motion and are termed as Microtubule Associated Proteins (MAPs). These two families of motor proteins transport membrane-bounded vesicles, proteins, and organelles along microtubules. Purified Xenopus melanosomes have been shown to possess bound kinesin and cytoplasmic dynein and to move on microtubules in vitro [63]. Nearly all kinesins move cargo toward the (+) end of microtubules (anterograde transport) also called plus-end directed motors, whereas dyneins transport cargo toward the (-) end (retrograde transport), oriented towards the cell center, also called "minus-end directed motors". The structure of molecular motors consists of two parts: a motor domain that reversibly bind to the cytoskeleton converting chemical energy contained in ATP into mechanical energy (motion) and the tail which is attached to the cargo. The divergent tail domains allow the motor to bind various types of organelles and particles via interactions with receptor proteins [64]. Xenopus melanophore plus-end directed movement (dispersion) has been shown to be driven by kinesin-II, a heterotrimeric kinesin of the kinesin super family which is found in many species. Kinesins typically contain two heavy chains with motor heads which move along microtubules via a pseudoprocessive asymmetric walking motion. It is formed by two homologous motor subunits of 85 and $95 \mathrm{kD}$ and a non-motor subunit of $115 \mathrm{kD}$, called kinesin-associated protein (KAP), which is thought to mediate cargo binding [65] (Figure 5).

Cytoplasmic dynein is responsible for the aggregation of pigment organelles in melanophores and consist of two heavy chains containing the motor domains as well as various intermediate, light intermediate and light chains [66, 64]. Like kinesin, cytosolic dynein is a two-headed molecule, with two nearly identical heavy chains forming 
the head domains. However, unlike kinesin, dynein cannot mediate transport by itself. Rather, dynein-related motility requires a large complex of microtubule-binding proteins that link pigment carrying melanosomes to microtubules but by themselves do not exert force to cause movement. Dynein has been shown to interact with many of its cargos, including pigment organelles, via dynactin [67, 64, 68]; which is a hetero-complex of at least ten subunits, including a 150,000-MW protein called Glued or p150 Glued), the actin-capping protein Arp1, and dynamatin or p50 [68]. The P150 Glued subunit plays a key role, in dynactin-dynein interaction by binding to the cytoplasmic dynein. In addition the p150Glued subunit of dynactin interact with the KAP subunit of kinesin II, thus serving as a receptor for kinesin II during dispersion of Xenopus melanosomes [68] (Figure 6).

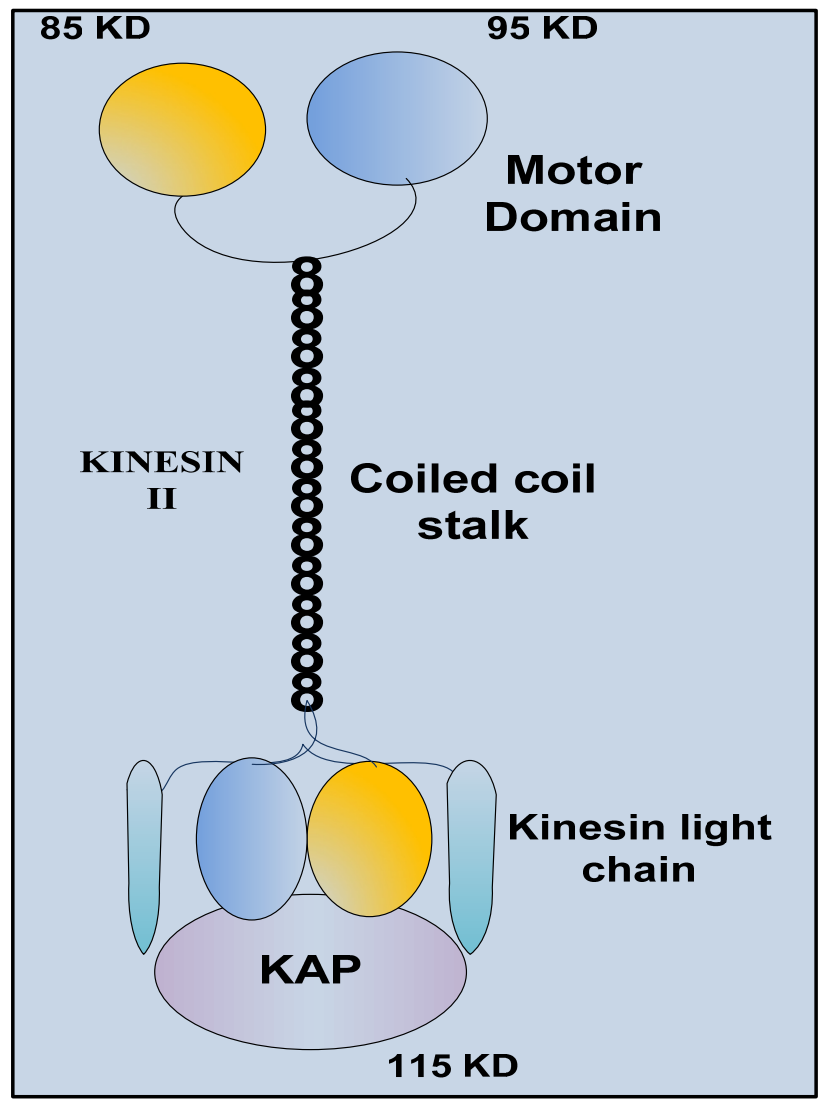

Figure 5. Kinesin II is a heterotrimeric motor protein. Motor heads shown in blue (95 KD) and orange (85 KD) and a non motor subunit shown in grey (115 KD) called kinesin-associated protein (KAP).The motor domains contain binding sites for cytoskeleton. The coiled-coil domain connects the motor domain to the tail domain. Kinesin light chain (KLC) binds through the globular tail domain of kinesin heavy chain (KHC). 


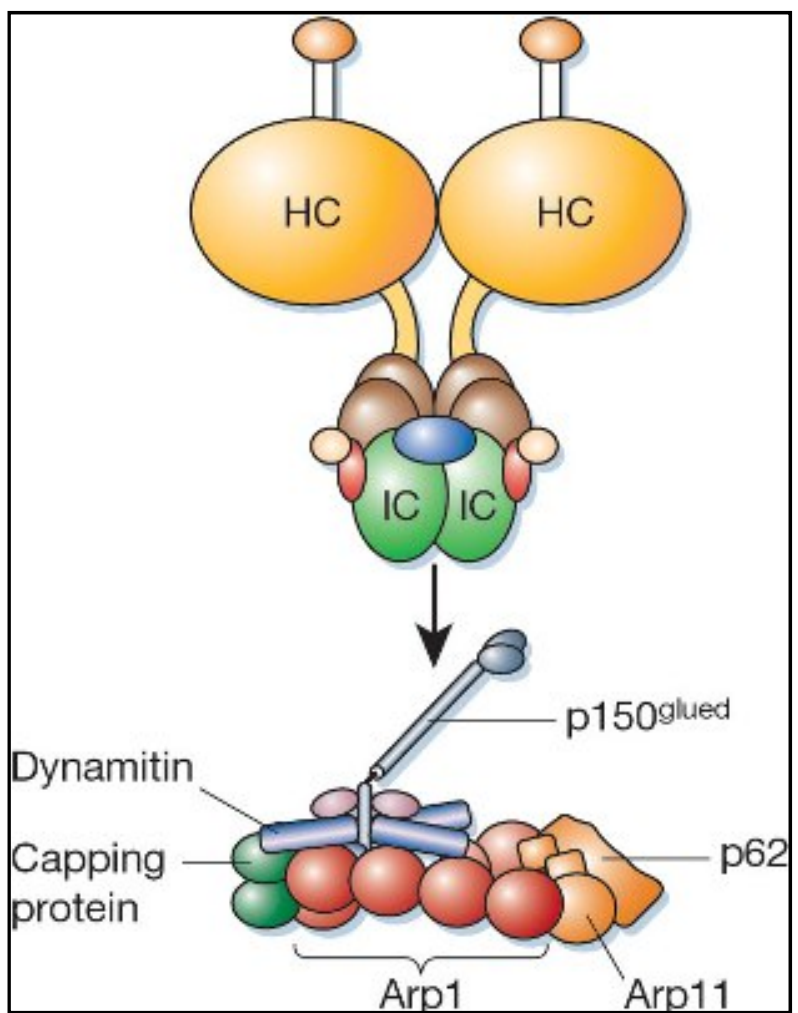

Figure 6. The dynein molecule, itself a complex of heavy (HC), intermediate (IC) and light chains, interacts with the p150glued subunit of the dynactin complex through its intermediate chains (arrow), although the precise mode of interaction is not known. The most prominent component of the dynactin complex is a short filament of the actin-related protein Arp1 (Reproduced with permission from Macmillan Publishers Ltd [107], Nature, Copyright (C 2003, Nature Publishing Group.

\subsubsection{Myosin $V$ is responsible for melanosome transport along actin filaments in xenopus}

Myosin $\mathrm{V}$ is the unconventional class $\mathrm{V}$ of the myosin family which is found in many different organisms $[69,70]$. It is composed of:

- The head domain that binds the filamentous actin, and uses ATP hydrolysis to generate force and to "walk" along the filament towards the barbed (+) end.

- The neck domain acts as a linker and as a lever arm for transducing force generated by the catalytic motor domain. The neck domain can also serve as a binding site for myosin light chains which are distinct proteins that form part of a macromolecular complex and generally have regulatory functions.

- The tail domain generally mediates interaction with cargo molecules and/or other myosin subunits. In some cases, the tail domain may play a role in regulating motor activity. 
Myosin Va binds to melanosomes through a complex of melanophilin and Rab27a, a small GTP-binding Ras-like GTPase (Figure 6) [71,47]. Rab27a first binds to the melanosome and then recruits melanophilin, who's N-terminal interact with the GTP- bound Rab27a. Subsequently myosin $\mathrm{Va}$, requiring binding of both Rab27a and melanophilin to the melanosome, is able to interact with the C-terminal portion of melanophilin [70, 71] (Figure 7).

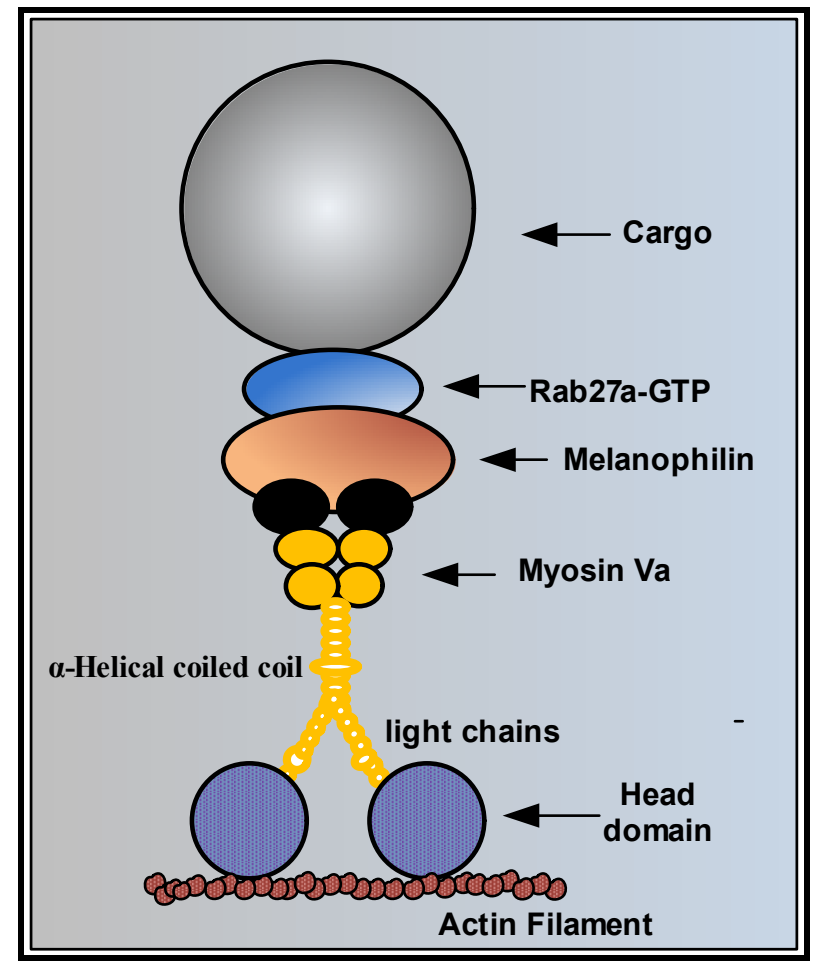

Figure 7. Mysoin Va binds to melanosomes through a complex of GTP-bound Rab27a and melanophilin. Rab27a binds to the melanosome first and then recruits melanophilin. Myosin Va requires the binding of both Rab27a and melanophilin before being able to interact with melanophilin.

During pigment translocation across the cells microtubules and actin filaments interact with several motors that bind to the same cargo (melanosome) at the same time. In Xenopus laevis melanophores the retrograde transport of melanosomes (aggregation) is driven by the molecular motor dynein along microtubules and anterogate movements (dispersion) by kinesin II and myosin Va along both microtubules and actin filaments. The actin filaments trap melanosomes at the cell periphery assuming an even distribution of pigment throughout the cell. It has been demonstrated [59] that the microtubule motor activity is coordinated while microtubule-actin based transport is competitive. During aggregation the myosin Va dependent transport is down regulated whereas the kinesin based transport predominate. The net movement of melanosomes results from the combined action of these three motors (Figure 8). 
However there are two different mechanisms postulated to explain the unidirectional (either aggregation or dispersion) transport of melanosomes attached to two opposing motor proteins. In the first model, the motors are involved in a competitive manner called the "tug of war" with the stronger motor determining the direction of motion at any given time. On the other hand the second model, there is coordination, so that when the melanosome moves in one direction the opposing motors are inactive.

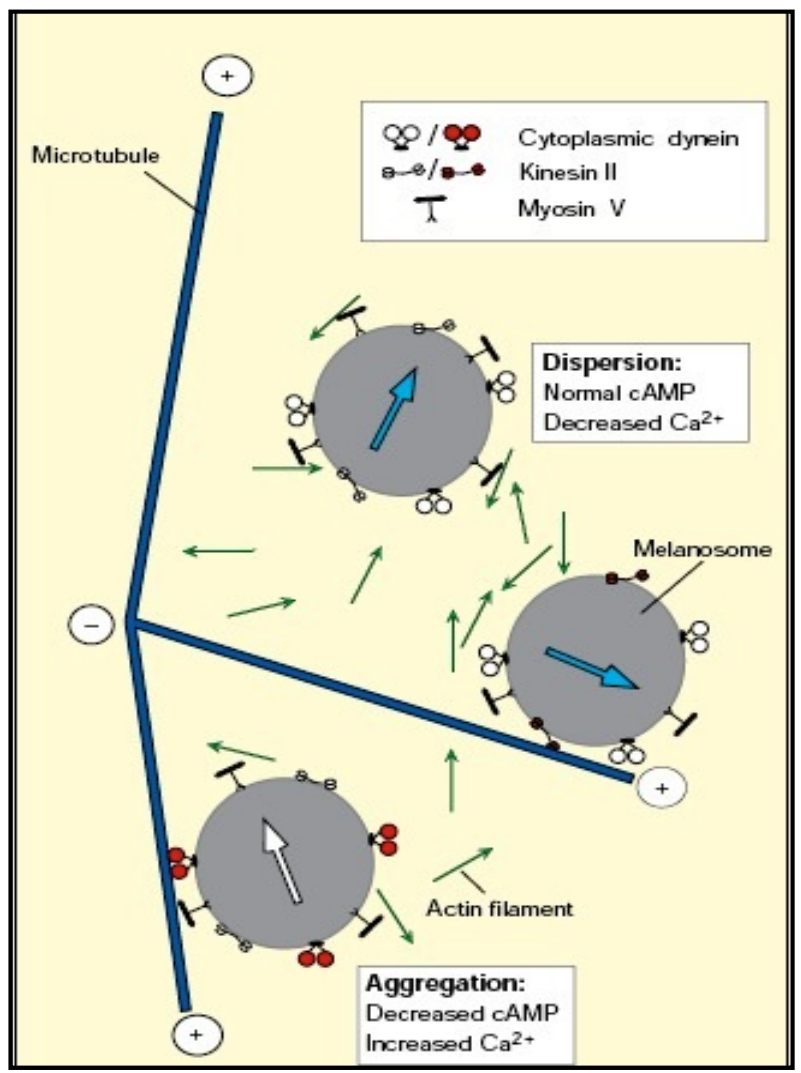

Figure 8. The external stimulation of pigment cells result into a highly coordinated bidirectional movement of pigment granule that either result into aggregation (movement towards the minus ends of microtubules, indicated by white arrow) or dispersion (movement towards the plus ends of microtubules and the periphery of the cell, indicated by a blue arrow). Melanosomes that are in the process of dispersion, move off microtubule tracks and then move along short, randomly-oriented actin filaments. 'Active' microtubule motors are indicated by red globular motor domains; 'inactive' microtubule motors are indicated by white motor domains. (Figure from reference [97]; Reproduced with permission from Elsevier, Copyright $\odot 1998$ Elsevier Science Ltd.

The process of pigment translocation within the pigment cells as evident from above discussion is a remarkably regulated phenomenon that involves the coordination of numerous cellular entities. Biochemical studies of melanosomes purified from aggregated and dispersed states 
have indicated that motor proteins remain attached to the melanosome even when their activity is not required; for example, kinesin II remains associated with melanosomes in an inactive state during melanocortin-induced pigment aggregation [58]. In contrast to mammalian cells, the motor activity in melanophores is acutely altered in a cAMP- and protein kinase A (PKA)dependent manner. Elevated cAMP results in increased kinesin activity, which leads to melanosome dispersion, whereas reduced cAMP results in increased dynein activity, which gives rise to aggregation [72]. PKA directly associates with melanosomal kinesin and dynein and might be recruited to melanosomes by the small GTPase Rab32 [73, 74].

Studies show that one to three dynein molecules can transport each melanosome in the minus end direction. The transport in the plus end direction is driven by one -two copies of kinesin II. The number of dyneins transporting a melanosome increases during aggregation, whereas the number of active Kinesin II stays the same during aggregation and dispersion. Thus the direction of net melanosome transport is regulated by the number of active dynein molecules [111]. Kinesin-II and dynein compete for the same binding site on p150Glued of dynactin [68]. During aggregation, the release of myosin V helps the dynein-mediated movement to 'win' over the kinesin-II mediated movement [59]. Also studies show that the long-range, bidirectional, microtubule-dependent melanosome movements, coupled with actomyosin Va-dependent capture of melanosomes in the periphery, is the predominant mechanism responsible for the centrifugal transport and peripheral accumulation of melanosomes in mouse melanocytes [71] (Figure 9).

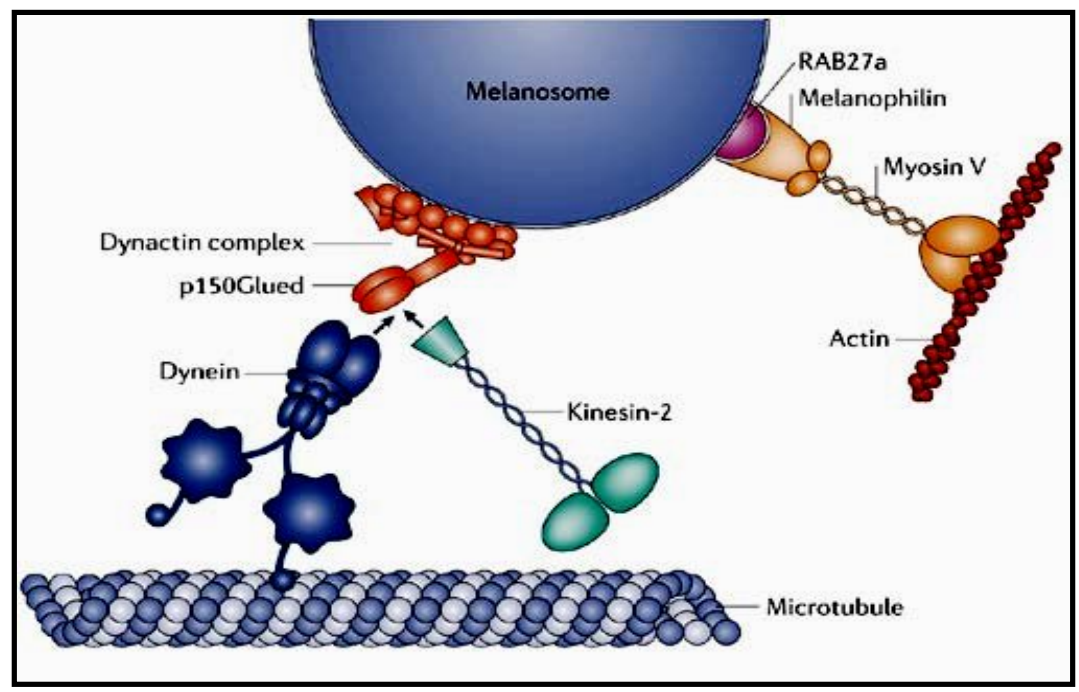

Figure 9. Coordinating several motors: the melanosome paradigm. (Reproduced with permission from Macmillan Publishers Ltd [110], Nature, Copyright @ 2006, Nature Publishing Group).

Gross et al.,[59] (Figure 10) have presented a very interesting model (Figure 10) that reflects how these motor proteins interact with the cytoskeletal tracks during melanosome transport. They have proposed that the pigment organelle can be moved in three different ways, along the 
microtubule by kinesin II (A and D) or by Dynein (B and E), or along the actin filaments by means of myosin $\mathrm{V}$ ( $\mathrm{C}$ and $\mathrm{F})$. It is proposed that the motion at any given moment is dominated by the two transport system i.e either action or microtubules. It is now known that the microtubule- and actin-based transport is not coordinated but rather competitive like in a "tugof-war". It has been observed that there has been a significant stimulation of microtubule-based motion due to a loss of myosin V function [71, 75] that clearly support that the microtubule- and actin-based transport are not coordinated but rather in a tug-of-war. , the motors of the other transport system are transiently active and interacting with their substrate (i.e., actin or microtubules). In their model they postulated that the motors of the other transport system are transiently active and interacting with their substrate (i.e., actin or microtubules) and during dispersion, these transient interactions (indicated by $\mathrm{T}$ ) are significant and allow myosin $\mathrm{V}$ to reduce the velocity of microtubule-based transport (A and B). The interactions also play a role in the switch between the two transport systems, that is, between B and C. Since myosin V activity predominantly decreases the length of minus end microtubule-based motion, the switch from microtubule- to actin-based transport occurs only between state B and C (from dynein movement to myosin $\mathrm{V}$ movement) and those transitions from kinesin II movement (A) to myosin $\mathrm{V}$ movement $(\mathrm{C})$ are rare. Because kinesin II but not dynein appears to win in tug-ofwars with myosin $\mathrm{V}$, we suggest that the $\mathrm{C}$ to $\mathrm{A}$ transition is possible but not the $\mathrm{C}$ to $\mathrm{B}$ transition; however, we have no direct evidence on this point. During aggregation, myosin $\mathrm{V}$ activity is decreased, which results in reduced weak transient interactions (indicated by weak T) in $\mathrm{D}$ and $\mathrm{E}$, and myosin $\mathrm{V}$ is no longer able to interfere with microtubule-based motion. Due to the weakness of the interactions, any time the microtubule motors are in contact with the microtubules they win the tug-of-war with myosin $\mathrm{V}$ and there is a transfer ( $\mathrm{F}$ to $\mathrm{D}$ or $\mathrm{F}$ to $\mathrm{E}$ ). Similarly, the reverse transfer from microtubules to actin-based transport ( $\mathrm{D}$ to $\mathrm{F}$ or $\mathrm{E}$ to $\mathrm{F}$ ) does not occur. M-V, myosin V; K-II, kinesin II; Dy, dynein; Ms, melanosome.

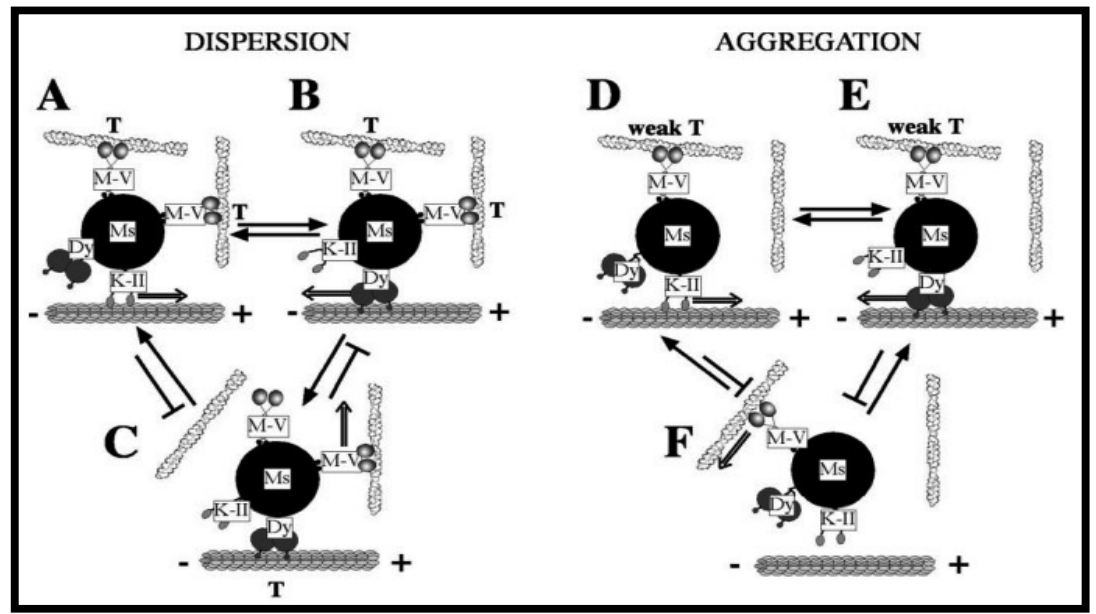

Figure 10. Model for transport of melanosomes by actin- and microtubule-based motors. Figure originally published in reference [59]; Gross et al., (2002) Interactions and regulation of molecular motors in Xenopus melanophores. J Cell Biol. 4;156(5):855-65.Copyright ( 2 2002.The Rockefeller University Press. 


\section{Melanophores as potential model for drug discovery}

The field of drug discovery is enormous with the development of novel and sensitive pharmaceutics and drugs that exert a distinguished response on targeted sites. On these grounds the noteworthy contribution of pigment bearing cells, melanophores cannot be overlooked. The fact that melanophores are highly specialized in bidirectional and coordinated translocation of pigment granules on given appropriate stimulus has conferred them as exceptional model system for pharmacological and physiological assays. The movement of pigment granules on external cues has been a highly coordinated phenomenon that requires an orchestrated and coordinated work of numerous cellular entities. This cellular connection depends largely on the transmission of signal couriers which are received via cell surface and intracellular recognition molecules (i.e. "receptors") on the recipient cells, resulting into remarkably coordinated bidirectional movement of pigment granules within the cells. Extensive pharmacological studies have devised the presence of various cell surface receptors (GPCR; G-protein coupled receptors) on these melanophores. Selective screening of these receptors has been a subject of investigation amongst researchers. The recognition of various ligands (agonists and antagonists) and characterizing their effects on pigment motility within the cells has answered many baffling questions regarding the complexed phenomenon of cellular motility and the signaling pathways that trigger pigment translocation.

Also the striking chromatic changes that occur are dependent on the cytoskeletal platforms that form the intricate networks within the cells and that these pigment motions are clearly microtubule dependent, since any disruption of microtubules blocks pigment dispersion and prevents directed pigment aggregation [39, 40,77]. In addition, it is now known that melanosome aggregation may be mediated by the retrograde microtubule-dependent motor protein dynein [76, 78] and dispersion is supported by the anterograde motor protein kinesin [80]. Therefore pigment motion within the melanophores could be a used as a revolutionary tool to study the possible relationship between microtubule dynamics and intracellular transport. Nonetheless the search is still on to bridge in the gap that still exists.

\subsection{Melanophores as bio-sensory opoids}

Selected G-protein coupled receptors can be functionally expressed in cultured frog melanophores. It has been demonstrated that the recombinant frog melanophores can be used as a biosensor for the detection of opoids. Transfection of melanophores with selected receptors enables the creation of numerous melanophore biosensors, which respond selectively to certain substances. The successful generation of in vitro cultures of these cells [51] has facilitated further characterization of melanophore cell signaling pathways and has made possible their use as a cell based reporter system [81]. The melanophore biosensor has potential use for measurement of substances in body fluids such as saliva, blood plasma and urine. Since the pigment granules, termed melanosomes, may be stimulated to undergo rapid dispersion throughout the melanophores (cells appear dark), or aggregation to the center of the melanophores (cells appear light). This simple physiological response, which 
can easily be measured in a photometer, has been used in a sensitive biosensor for catecholamine in blood plasma and pertussis toxin in saliva, based on melanophores in isolated fish scales [82, 83]. The melanophores are also an attractive model for studies in pharmacology, for drug design and in cytotoxicity screening [84]. Odorant, pheromone, and gustatory receptors all belong to the GPCR family, suggesting that melanophore biosensors, expressing the appropriate receptor, may also be a new principle for odor, pheromone, and taste sensing [86]. In an interesting report by De-Camp et al. [87] a 7-pass trans-membrane protein "Smoothened" was investigated for its ability to act as a G-protein-coupled receptor in immortalized Xenopus laevis melanophores. Cells expressing the protein showed a phenotype of persistent pigment aggregation, a hallmark of constitutive Galpha(i) activation. The findings demonstrated that the human Sonic hedgehog receptor complex can be functionally reconstituted in melanophores and that it is capable of trans-membrane signaling by utilizing endogenous Galpha(i).

According to Karlsson et al., [85] the melanophores of Xenopus laevis show a fast response initially, although it takes about $1 \mathrm{~h}$ to get maximal aggregation response. However, detection of melanosome movement can be noticed after a few minutes. If an even faster response is desired, development of fish cell lines might be an interesting alternative. For example, fish melanophores aggregate within 5 s after sympathetic nerve stimulation [88] and within 30s after light stimulation [89]. Owing to the super sensitivity of fish melanophores, the detection of signaling cues or compounds may be detected on a faster pace. However, a fish melanophore cell line has to be developed to allow efficient introduction of foreign receptor genes. The zebra fish stem cell line might be an attractive way to achieve above-mentioned goals [90]. Alternatively, the melanophores of frog can be manipulated to increase the speed of pigment aggregation [86].

\subsection{Zebrafish melanophore model}

Zebrafish model system has emerged as one of the most reliable systems for studies related to developmental gene function and disease processes in nervous system. During the past 20 years zebrafish has served as an excellent model for understanding normal development and birth defects based on its powerful genetics and exquisite embryology. For example, recent breakthroughs made in zebrafish include the isolation of a human skin color gene, the development of a melanoma model, and the isolation of a chemical that can correct cardiovascular defects. As vertebrates they possess a brain structure similar to that found in mammals. The intracellular signaling downstream of hormone stimulation and the biomechanical processes involved in zebrafish pigment translocation, has confirmed the importance of cyclic adenosine monophosphate (cAMP) as a mediator of pigment translocation and the presence of intact microtubules essential for both melanin dispersion and aggregation, has rendered it as an experimental model for studying both physiological color change and the molecular basis of pigment translocation [91]. Also in the recent years zebrafish melanophore model has been used to study melanocyte biology and melanoma [92]. Due to its prolific reproduction and the external development of the transparent embryo, the zebrafish serve as a cutting edge tool for genetic and developmental studies, as 
well as research in toxicology and genomics. Zebrafish melanophores are externally visible, and single cells can be visualized in a living animal. Zebrafish melanocytes retain melanin unlike mammals where the melanin pigment-containing melanosomes are transported to neighboring keratinocytes. For this reason zebrafish melanocytes can serve as a reliable and useful cell-type marker. Furthermore, the characteristic pattern of pigment cells in the zebrafish skin, combined with newly developed techniques molecular genetics, makes the zebrafish an ideal experimental system for the evaluation of melanogenic regulatory compounds and the mechanism of pigmentation pattern formation $[93,95,96]$.

Since a growing number of diseases, including neuropathology and developmental disorders, are thought to result from disrupted transport of organelles, the regulation of molecular motor proteins by applying genetics to the problem of melanosome transport in zebrafish melanophores could be used as a promising tool in investigating such problems. This will be accomplished by screening zebrafish mutants specifically for alterations in melanosome dynamics. Mutants of interest can be examined by isolating their melanophores via live cell imaging and characterizing their defects in pigment transport [94].

\section{Future directions}

Our earlier impression of cell has been completely reconditioned with the novel concepts that has brought cell to be a dynamic rather than a rigid entity. The regulation of normal responsiveness of a pigment cell result from dynamic interaction of cytoskeletal processes, molecular motor proteins and associated regulatory processes that are viewed as complex and integrated array of events. How do cells regulate this complex array of motor proteins and their interaction to control the trafficking of same cargo across the cells? Future investigations of melanosome dynamics promise to answer questions about how motor proteins and their motility are controlled and coordinated. The ability to isolate biochemically-defined melanosomes in large quantities from cultured melanophores, coupled with in vitro motility assays to test the activity of specific motors under different conditions, provide a great opportunity to gain insights into how these complex interactions are regulated [97]. Fish melanophores are a classical example [98] of a cell highly specialized in intracellular microtubule-dependent transport, and it is worth considering whether microtubule polymerization and de-polymerization in these cells may be directly coupled to the translocation of pigment organelles [50]. The direct observation and manipulation of cultured melanophores will provide ways to draw conclusions from the in vitro experiments and expand our understanding of this mechanism. These experiments would provide deeper insights into the control and coordination of motility for a variety of cargos in different eukaryotic cell systems [97]. It is known that several genetic disorders in mice and humans are linked to disrupted intracellular organelle transport. The recent characterization of genes defective in these diseases has drawn immense interest in the melanosome as a model system for understanding the molecular mechanisms that underlie intracellular membrane dynamics [99]. The regulation of normal cellular morphology is a highly concerted system that must integrate the temporal-spatial control of multiple cellular 
processes, including cytoskeletal and membrane dynamics. Since cells interact with other cells through their surfaces, therefore cellular phenotypes are a dynamic process that reflects the influence of other cells. On these grounds we emphasize upon the role of pigment cells and their dynamics that might help to better comprehend the dynamics of other cellular entities like the muscle cells and vice versa. The study of these cellular systems would significantly contribute towards comprehension of both physiological and pathological events related to muscle as well as pigment cells.

\section{Author details}

\section{Saima Salim}

Pigment Biology, Saifia College Bhopal, India

Sharique A. Ali*

Physiology and Department of Biotechnology at Saifia College Bhopal, India

\section{References}

[1] Spaeth RA. Evidence proving melanophores as disguised type of Smooth muscle cells. Journ of Exp Zool. 1917; 20: 2,193-215.

[2] Webb CR. Smooth Muscle contraction and Relaxation. Adv Physiol Educ.2003; 27; 4, 201-206.

[3] Riento K, Ridley AJ. "Rocks: multifunctional kinases in cell behaviours". Nat Rev Mol Cell Biol. 2003; 4, 6: 446-456.

[4] Vesely DL, Hadley ME Ionic requirements for melanophore stimulating hormone (MSH) action on melanophores. Comp. Biochem. Physiol. 1979; 62A:501-507.

[5] Hadley ME. Endocrinology, 5th Edition, Printice Hall. 1988.

[6] Zhang F, Wang Li-P, Boyden ES, Deisseroth K.Channelrhodopsin-2 and optical control of excitable cells. Nature Methods, 2006; 3:10, 785-792.

[7] Aspengren S, Hedberg D,Wallin M.Melanophores: A model system for neuronal transport and exocytosis? Journ of Neuro Res. Sp Issue Intraneural Transport. 2006;85: 12, 2591-2600.

[8] Salim S, Ali SA. Vertebrate melanophores as potential model for drug discovery and development: a review. Cell Mol Biol Lett. 2010; 6,1:162-200.

[9] Redfield AC.The Physiology of the melanophores of the horned toad Phrynosoma. Journ of Exp Zool. 1918; 26:2, 275-333.

[10] Smith DC. Melanophore Pulsations in the isolated scales of Fundulus heteroclitus. Proc. Nat. Am Soc. 1930; 16:381-385.

[11] Parker GH. Animal Color changes and their Neurohumors. Quat. Rev of Biol. 1943; 18:3, 205-227.

[12] Messenger JB. Cephalopod chromatophores: neurobiology and natural history. Biol. Rev. 2001;76: 473-528.

\footnotetext{
${ }^{*}$ Corresponding author
} 
[13] Franz V. Beobachtungen am lebenden Selachierauge.Jenaische Zeitschr. f. Naturwiss., 41(Nf.Bd. 34) 1906; 429-471.

[14] Pouchet G. Color changes in crustaceans and fishes. J. Anat. Physiol. 1876; 12:1-90, 113116.

[15] Brücke E. Untersuchungen uber den Farbenwechsel des afrikanischen Chamaleons. Denschr. Akad. Wiss. Wien, Mathnat. Kl, 1852; 4:179.

[16] Parker GH. Animal colour changes and their neurohumors. Cambridge Univ. Press, Cambridge. (U.K) 1948.

[17] Fujii, R. Cytophysiology of fish chromatophores. Int Rev Cytol. 1993; 143: 191-255.

[18] Canning BJ. Reflex regulation of airway smooth muscle tone. Jour of App. Physiol. 2006; 101, 3: 971-985.

[19] Sherwood L. Fundamentals of Human Physiology 4/E. The Muscle Physiology, pp 185186. Cengage learning, 2011.

[20] Van De Graaff, Fox SI. Concepts of human anatomy and physiology. W.C Brown.Cornell University.1986

[21] Pouchet G. Des changements de coloration sous I'innuence des neK J. Anat Paris 1876; 12: 1-90, 113-165.

[22] Miyata S Yamada K. Innervation pattern and responsiveness of melanophores in tail fins of teleosts. Journ of Experim Zool. 1987; 241: 1, 31-39.

[23] Pye JD. Nervous control of chromatophores in teleost fishes. I I. T he influence of certain drugs in the minnow (Phoxinus phoxinus (L.)). J. Exp. Biol.1964; 41, 535-41-

[24] Frisch VK. Beitrage zur Physiologic der Pigmentsellen in der Fischhaut. Pflugers Arch.Gesante Physiol. Menschen Tiere. 1911; 138: 319-387.

[25] Hertel. Ztschr. F.allag. Physiol. 1907; 6,44.

[26] Kargacin GJ, Detwiler PB. Light-evoked Contraction of the Photosensitive Iris of the Frog' The Journ. of Neurosc. 1985; 5: 11,3081-3087.

[27] Schliwa M, Bereiter-Hahn. Pigment movements in fish melanophores: Morphological and physiological studies. Cell and Tiss. Res. 1975; 158:1, 61-73

[28] Winkler.Arch. F. Derm. U. Syphilis. 1910; 101, 255.

[29] Bert P. Compt. Rend., 1975; 81, 938.

[30] Krukenberg CF. I-Vergleich, Physiol.Studien, 1 Reihe, 1.1881.

[31] Kapoor BG Khanna B. Integument: Dermal Skeleton Coloration and Pigment Cells. 6573. Ichthyology Handbook, Springer.2004.

[32] Thaler CD, Haimo LT. Control of organelle transport in melanophores: Regulation of $\mathrm{Ca}^{2+}$ and cAMP levels. Cell Motility and Cytoskeleton. 2005; 22:175-184.

[33] Novales RR. The effect of the divalent cation ionophore A23187 on amphibian melanophores and iridophores. J Invest Dermatol. 1977; 69:446-50.

[34] Tuma CM, Gelfand VI. Molecular mechanism of Pigment Transport in melanophores. Pigm. Cell Res. 1999;12:5, 283-294.

[35] Fujii R, Fujii $\Upsilon$. Mechanism of nervous control of fish melanophores. IL Role of divalent ions in the transmission at the melanin-aggregating nerve endings; Zool. Mag. 1965; 74351.

[36] McNiven MA, Porter KR. Chromatophores-models for studying cytomatrix translocations. J. Cell Biol. 1984; 99:152s-158s. 
[37] Schliwa, M. Review article: permeabilized cell models for the study of granule transport in pigment cells. Pigm. Cell Res.1978;1:65-68.

[38] Haimo LT, Rozdzial, MM. Lysed chromatophores: a model system for the study of bidirectional organelle transport. Methods Cell Biol.1989; 31: 3-24.

[39] Schliwa M, Bereiter-Hahn J. Pigment movement in fish melanophores. III. The effects of colchicine and vinblastine. Z. Zellforsch. 1973; 147:127-148.

[40] Murphy DG, Tilney LG..The role of microtubules in movement of pigment granules in teleost melanophores.J. Cell Biol. 1974; 61:757-779.

[41] Obika M, Negishi S. Effects of hexylene glycol and nocodazole on microtubules and melanosome translocation in melanophores of the Medaka, Oryzias latipes. J. Exp. Zool. 1985; 235: $55-63$.

[42] Luby-Phelps K, Porter KR The control of pigment migration in isolated erythrophores of Holocentrus ascensionis (Osbeck). II. The role of calcium. Cell. 182; 29:441-450.

[43] Oshima N, Suzuki M, Yamaji N, Fujii.R Pigment aggregation is triggered by an increase in free calcium ions within fish chromatophores. Comp. Biochem. Physiol. 1988; 9 1A: 27- 32

[44] McNiven M.A, Ward JB. Calcium regulation of pigment transport in vitro. J. Cell Biol.1988; 106:111-125.

[45] Rochow VBM, Royuela M. Calponin, Caldesmon and chromatophores: the smooth muscle connection. Microscopy Res. and Technique. Sp Issue:Biol of Pig Cells in fish.2002; 58:6, 504-513.

[46] Rochow VBM, Royuela, Fraile B, Paniagua R Smooth muscle proteins as intracellular components of the chromatophores of the Antarctic fishes Pagothenia borchgrevinki and Trematomus bernacchii (Nototheniidae). Protoplasma , 2002; 218, : 1-2, 24-30.

[47] Nascimento AA, Roland JT, Gelfand VI. Pigment cells: a model for the study of organelle transport. Annu Rev Cell Dev Biol. 2003; 19:469-91.

[48] Bikle D, Tilney LG, Porter KR. Microtubules and pigment migration in the melanophores of Fundulus heteroclitus. Protoplasma.1966; 61, 322-345.

[49] Schliwa, M. Mechanisms of intracellular transport. Cell and Muscle Motility (Shay, J. W. ed) $1984 ; 5: 1-81$.

[50] Rodionov VI, Nadezhdina ES, Borisy GG. Centrosomal control of microtubule dynamics. Proc. Natl. Acad. Sci. USA 1999; 96, 115-120.

[51] Vallee RB, Wall JS, Paschal BM. The role of dynein in retrograde axonal transport, TINS, 1989; 12:66-70.

[52] Schnapp BJ, Vale RD, Sheetz MP, Reese TS. Single microtubules from squid axoplasm support bidirectional movements of organelles, Cell. 1985; 40: 455-462.

[53] Byers HR, Yaar M, Eller MS, Jalbert NL, Gilchrest BA. Role of cytoplasmic dynein in melanosome transport in human melanocytes. J. Invest. Dermatol.2000; 114, 990-997.

[54] Hara M, Yaar M, Byers HR, Goukassian D, Fine R E, Gonsalves J, Gilchrest BA. Kinesin participates in melanosomal movement along melanocyte dendrites. J. Invest. Dermatol. 2000; 114: 438-443.

[55] Wu XS, Tsan GL, Hammer JA, 3rd. Melanophilin and myosin Va track the microtubule plus end on EB1. J. Cell Biol 2005. 171; 201-207. 
[56] Vancoillie G, Lambert J, Mulder A, Koerten HK, Mommaas AM, Van Oostveldt P, Naeyaert JM. Cytoplasmic dynein colocalizes withmelanosomes in normal human melanocytes. Br. J. Dermatol. 2000; 143:298-306.

[57] Daniolos A, Lerner AB, Lerner MR. Action of light on frog pigment cells in culture. Pigment Cell Res.1990; 3, 38-43.

[58] Reilein AR, Tint IS, Peunova NI, Enikolopov GN, Gelfand VI. Regulation of organelle movement in melanophores by Protein Kinase A (PKA), Protein Kinase C and Protein Phosphatase 2A (PIP2). JCB, 1998; 142:3, 803-813.

[59] Gross SP, Tuma CM, Deacon SW, Serpinskaya AS, Reilein AR, Gelfand VI. Interactions and regulation of molecular motors in Xenopus melanophores. J. Cell Biol. 2002; 156, 855-865.

[60] DePina AS, Langford GM. Vesicle transport: the role of actin filaments and myosin motors. Microsc. Res. Tech. 1999; 47, 93-106.

[61] Gundersen GG, Cook TA. Microtubules and signal transduction. Curr. Opin. Cell Biol.1999; 11, 81-94.

[62] Pollard TD, Borisy GG.Cellular motility driven by assembly and disassembly of actin filaments. Cell 2003;:112:453-65.

[63] Rogers SL, Tint LS, Fanapour PC, Gelfand VI. Regulated bidirectional motility of melanophore pigment granules along microtubules in vitro. Proc. Natl. Acad. Sci. USA.1997; 94:3720-3725.

[64] Karcher RL, Deacon SW, Gelfand VI. Motor-cargo interactions: the key to transport specificity. Trends Cell Biol. 2002;12, 21-27.

[65] Tuma MC, Zill A, Le Bot N, Vernos I, Gelfand V. Heterotrimeric kinesin II is the microtubule motor protein responsible for pigment dispersion in Xenopus melanophores.J. Cell Biol.1998; 143:1547-1558.

[66] Nilsson, H, Wallin M. Evidence for several roles of dynein in pigment transport in melanophores. Cell Motil. Cytoskeleton.1997; 38:397-409.

[67] Hirokawa N. Kinesin and dynein superfamily proteins and the mechanism of organelle transport. Science.1998; 279 :519-26.

[68] Deacon SW, Serpinskaya AS, Vaughan PS, Lopez Fanarraga M, Vernos I, Vaughan KT, Gelfand VI.. Dynactin serves as a receptor for kinesin II on Xenopus laevis melanosomes. J. Cell Biol. 2003; 160:297-301.

[69] Rogers SL, Gelfand VI. Myosin cooperates with microtubule motors during organelle transport in melanophores. Curr. Biol. 1998; 8:161-164.

[70] Fukuda M, Kuroda TS, Mikoshiba K.. Slac2-a/melanophilin, the missing link between Rab27 and myosin Va: implications of a tripartite protein complex for melanosome transport. J. Biol. Chem. 2002; 277, 12432-12436.

[71] Wu X, Wang F, Rao K, Sellers JR Hammer JA 3d. Rab27a is an essential component of melanosome receptor myosin Va. Mol Biol. Cell 2002; 13, 1735-1749.

[72] Rodionov V, Yi J, Kashina A, Oladipo A, Gross SP. Switching between microtubule- and actin-based transport systems in melanophores is controlled by cAMP levels. Curr. Biol.2003; 13, 1837-1847. 
[73] Kashina AS, Semenova IV, Ivanov PA, Potekhina ES, Zaliapin I, Rodionov VI. Protein kinase A, which regulates intracellular transport, forms complexes with molecular motors on organelles. Curr. Biol. 2004; 14, 1877-1881.

[74] Park M, Serpinskaya AS, Papalopulu N, Gelfand VI. Rab32 regulates melanosome transport in Xenopus melanophores by protein kinase A recruitment. Curr. Biol. 2007; 17, 2030-2034.

[75] Bridgman, PC. Myosin Va movements in normal and dilute-lethal axons provide support for a dual filament motor complex. J. Cell Biol. 1999; 146:1045-1060.

[76] Beckerle MS, Porter KR. Inhibitors of dyne in activity block intracellular transport in erythrophores. Nature (Lond.) 1982; 295:701-703.

[77] Beckerle MC, Porter KR. Analysis of the role of microtubules and actin in erythrophore intracellular motility. J. Cell Biol. 1983; 96:354-362.

[78] Ogawa KH, Hosoya E, Yokota T, Kobaya shi, Wakamatsu Y, Ozato K (1987) Melanoma dynein: evidence that dyne in is a general "motor" for microtubule-associated cell motilities. Fur. J. Cell Biol 1987;43: 3-9.

[79] Rodionov VI, Gyoeva FK, Gelfand VI. Kinesin is responsible for centrifugal movement of pigment granules in melanophores. Proc. Natl.Acad. Sci. USA. 1991; 88:4956-4960.

[80] Jayawickreme CK, Kost TA. Gene expression systems in the development of highthroughput screens. Curr. Opin. Biotechnol. 1991; 8: 629-634.

[81] Lundström I. Gustafsson A., Ödman, S. Karlsson JOG , Andersson RGG, .Grundström, Sundgren N, Elwing H (1990). Fish scales as biosensors. Sensors \& Actuators: B. Chemical 1990; 1-6: 533-536.

[82] Karlsson JOG, Grundsrom, Elwing H, Andersson RGG. The fish pigment cell; An alternative model in biochemical research. ATLA, 1990; 18:201-224.

[83] Lundstrom I, Svensson S. Biosensing with G-protein coupled receptor systems. Biosens and Bioelectron. 1998;13, $689-695$.

[84] Karlsson AM, Lerner MR, Unett D, Lundström I, Svensson SP. Melatonin-induced organelle movement in melanophores is coupled to tyrosine phosphorylation of a high molecular weight protein. Cell Signal.; 2000; 12:469-74.

[85] Karlsson AM, Bjuhr K, Testorf M, Oberg PA, Lerner E, Lundstrom I, Svensson SPS. Biosensing of opioids using frog melanophores. Biosens and Bioelectron.2002; 17: 331-335.

[86] DeCamp DL, Thompson TM, de Sauvage FJ, Lerner MR Smoothened activates Galphaimediated signaling in frog melanophores. J. Biol Chem; 2000; 275:26322-26327.

[87] Svensson SP, Adolfsson PI, Grundström N, Karlsson JO. Multiple alpha 2-adrenoceptor signalling pathways mediate pigment aggregation within melanophores.Pigment Cell Res.1997; 10:395-400.

[88] Oshima N, Nakata E, Ohta M, Kamagata S. Light-induced pigment aggregation in xanthophores of the medaka, Oryzias latipes. Pigment Cell Res. 1998;11, 362-367.

[89] Ma C, Fan L, Ganassin R, Bols N, Collodi P. Production of zebrafish germ-line chimeras from embryo cell cultures. Proc. Natl. Acad. Sci. USA. 2001; 98, 2461-2466.

[90] Logan DW, Burn SF, Jackson IJ. Regulation of pigmentation in zebrafish melanophores. Pigment Cell Res.2006; 19:206-13.

[91] Ceol CJ, Houvras Y, White RM, Zon LI. Melanoma biology and the promise of zebrafish. Zebra fish. 2008; 5:247-255. 
[92] Choi TY, Kim JH, Ko DH, Kim C-H, Hwang J-S, Ahn S, Kim SY, Kim C-D, Lee J-H, Yoon T-J. Zebrafish as a new model for phenotype-based screening of melanogenic regulatory compounds. Pigment Cell Res. 2007; 20:120-127.

[93] Lavinia Sheets. Regulation of Molecular Motors in Zebrafish.2007 http://www.researchgrantdatabase.com/g/5F31GM071198-03/Regulation-of-MolecularMotors-in-Zebrafish/

[94] Takahashi G, Kondo S. Melanophores in the stripes of adult zebrafish do not have the nature to gather, but disperse when they have the space to move. Pigment Cell Melanoma Res. 2008; 21:677-686.

[95] Newman M, Wilson L, Camp E, Verdile G, Martins R, Lardelli M. A zebrafish melanophoremodel of amyloid beta toxicity. Zebrafish.. 2010; 7:155-159.

[96] Kelleher JF and Margaret AT. Intracellular motility: How can we all work together?. Current Biology, 1998; 8:R394-R397.

[97] Bikle D, Tilney LG, Porter K.R. Microtubules and pigment migration in the melanophores of Fundulus heteroclitus. Protoplasma. 1966; 61:322-345.

[98] Marks MS, Seabra MC. The melanosome: membrane dynamics in black and white. Nature Reviews Molecular Cell Biology, 2001; 2, 10: 738-748.

[99] Ghalayini IF. Nitric oxide-cyclic GMP pathway with some emphasis on cavernosal contractility. Internat. Journ. of Imp. Res. 2004; 16: 459-469.

[100] Castrucci AM, Hadley ME, Lebl M, Zechel C, Hruby VJ. Melanocyte stimulating hormone and melanin concentrating hormone may be structurally and evolutionarily related. Regulatory Peptides. 1989; 24: 27-35.

[101] Negi CN. " Regulation of Pigmentation: Pars Intermedis". Introduction to Endocrinology. PHI learning Ltd. New Delhi. 2009;. 113-115.

[102] Karaki H, Ozaki H, Hori M, Mitsui-Saito M, Amano K, Harada K, Miyamoto S, Nakazawa H, Won KJ, Sato K.. Calcium movements, distribution, and functions in smooth muscle. Pharmacol Rev 1997; 49:157-230.

[103] Fujii R, Novales R. Cellular aspects of the control of physiological color changes in fishes. Integ and Comp Biol. 1969; 9: 453-463.

[104] Bagnara JT, Hadley ME. Chromatophores and color changes. Prentice-Hall, Inc, Englewood Cliffs, N. J. 1973.

[105] Wakamatu Y. Light-sensitive fish melanophores in culture. J. exp. Zool. 1978. 204:299-304.

[106] Schliwa M, Woehlke G. Molecular Motors. Nature. 2003.422: 759-765.

[107] Nilsson HM, Karlsson AM, Loitto VM, Svensson SP, Sundqvist T. Nitric oxide modulates intracellular translocation of pigment organelles in Xenopus laevis melanophores. Cell Motil Cytoskeleton 2000;.47:209-218.

[108] Hayashi H, Fujii R.. Possible involvement of nitric oxide in signaling pigment dispersion in teleostean melanophores. Zoolog Sci.2001;18:1207-1215.

[109] Soldati T, Schliwa M. Powering membrane traffic in endocytosis and recycling. Nature Rev. Molec Cell Biol.2006; 7: 897-908.

[110] Levi V, Serpinskaya A, Gratton E, Gelfand V. Organelle Transport along Microtubules in Xenopus Melanophores: Evidence for Cooperation between Multiple Motors. Biophys J 2006; 90: 318-327. 